www. revistad yo. com

\title{
A pilot model for the liberalization of the Spanish railway market based on combina- torial auctions
}

\author{
David Poza, Félix A. Villafáñez, Eduardo Navas, Javier Pajares, Adolfo López-Paredes
}

Recibido: 30 de Octubre de 2019

Aceptado: 05 de Noviembre de 2019

https://doi.org/10.37610/dyo.v0i70.571

\begin{abstract}
The liberalization of the railway market in the European Union brings the need to define a competitive mechanism that allows the infrastructure manager to allocate the rights of use of railway segments to the new emerging train operating companies. For this allocation process, we propose the use of combinatorial auctions, a mechanism that has provided successful results in the liberalization of other markets such as the radio spectrum. In this context, the aim of this paper is to provide a high-level description of a pilot model for the liberalization of the Spanish railway market based on combinatorial auctions.
\end{abstract}

\section{Keywords}

Market liberalization, railway market, railway scheduling, Spanish railway network, combinatorial auction.

\section{Introduction}

Railway scheduling is a process whose objective is to find a feasible timing so that a set of trains can operate without conflicts through a railway network during a certain period (Schlechte 2011).

Railway scheduling has been carried out since the origins of rail transport. Traditionally it was done manually, starting from a current schedule on which incremental modifications were made to improve the original schedule on a trial-anderror basis (Borndörfer et al. 2006). However, over the last few decades, numerous proposals for mathematical optimization models have been introduced, which has resulted in the first steps towards addressing and automating these operations (Schlechte 2011).

David Poza *
poza@insisoc.org
ORCID ID: 0000-0002-9878-221X
Félix A. Villafáñez*
felixantonio.villafanez@uva.es
ORCID ID: 0000-0001-7927-8627
Eduardo Navas *
educreal@hotmail.com
ORCID ID: 0000-0002-4314-4448
Javier Pajares*
pajares@insisoc.org
ORCID ID: 0000-0002-4748-2946
Adolfo López-Paredes *
adolfo@insisoc.org
ORCID ID: 0000-0001-5748-8308
* INSISOC - University of Valladolid. Paseo del Cauce 59,
Valladolid, 47011. Spain

Several factors have led to the research of new mechanisms that allow a more efficient use in the railway infrastructure.

One of these factors has been the liberalization of railway transport. For example, several European Union's directives for the reorganization of the Railway System 2013/0015(COD) and 2013/0028(COD) - promote the separation of the traditional railway activities. These directives promote that, in each State, there is a single company that manages the railway infrastructure (whose responsibility includes, among other activities, the scheduling of train timetables, real-time control. etc.) and several train operating companies (who will be responsible for providing the trains and the freight or passenger transport services). Consequently, several train operating companies will need to compete to access a common infrastructure so that they can provide the transport services. This situation opens a new market since traditionally there has been only one train operating company in each European state. Having several operating companies instead of only one will lead to greater potential conflicts due to the increase of the requests for infrastructure from the new operating companies. This competition encourages an improvement of the existing allocation models in order to achieve a more efficient use of railway infrastructure (Borndörfer et al. 2012).

A second factor has been the effect of the privatization of railway companies in Europe over recent years (Caprara et al. 2001). Since railway scheduling was traditionally carried out within the same company, the only goal of the process was to achieve a conflict-free timing for the company's own trains. However, after the market liberalization, the presence of multiple operators aiming to maximize their own 
profit has brought a second objective beyond obtaining a conflict-free schedule: the allocation of railway segments to operating companies needs to be efficient from an economic point of view, so that each infrastructure segment is assigned to the company that values it most.

These two factors have meant a redefinition of the classical railway scheduling problem, to which researchers have tried to shed light on over the last few years (Borndürfer et al. 2015). Formally, the aim is to find simultaneously a route for each train within the network so that the limited capacity of the network is respected, and at the same time, a series of operational restrictions are met while maximizing some characteristics of the network.

In the current version of the railway scheduling problem, there are two parties involved: on the one hand, railway operators need to elaborate a timetable that satisfies their customer's demand. On the other hand, the company that manages the infrastructure (i.e. a state-owned company) must decide how to allocate the available railway sections according to the requests from the operating companies (Schlechte et al. 2011), bearing in mind that conflicts between those requests are likely to occur. Furthermore, the development of allocation and optimization models is relatively recent because railway companies operated as a de facto monopoly for a long time (Borndürfer et al. 2015) and thus there were no incentives to optimize and standardize planning tasks.

Consequently, the liberalization of the railway market in the European Union brings the need to define a mechanism that allows the infrastructure manager to allocate the rights of use of railway segments to the new emerging train operating companies. For this allocation process, we propose the use of combinatorial auctions, a mechanism that has provided successful results in the allocation of scarce resources.

In this context, the objective of this paper is to provide a high-level description of a pilot model for the liberalization of the Spanish railway market based on combinatorial auctions. To this aim, in Section 2 we provide a literature review on the railway scheduling problem, whose resolution belongs to NP (Caprara, A et al., 2002; Garey \& Johnson, 1979), which means that it is not possible to find an optimal solution in a polynomial time. Bearing in mind the NP nature of the problem, in Section 3 we focus on the latest research on mechanisms for the allocation of railway segments in the context of the liberalization of the railway market. We find that most of the approaches so far have resorted to methods that entail a large number of simplifications to obtain an approximate solution. In Section 4 we propose to use combinatorial auctions as an allocation mechanism, as it has been widely used in allocation problems after the liberalization of other markets. In Section 5 we describe our contribution: a pilot model for the liberalization of the Spanish railway based on combinatorial auctions. Finally, we will present the conclusions of this work.

\section{Background on railway scheduling}

Railway scheduling (i.e. finding a feasible timing so that a set of trains can operate without conflicts through a railway network during a certain period) is such a complex problem that it cannot be considered simultaneously in all its extension (Schlechte 2011).

A model that incorporates all the complexity of a railway network, including details such as the exact number of tracks, the number of platforms in each station, signaling, different types of trains and their dynamic characteristics, etc., would provide a truly precise schedule. Unfortunately, such a complex model would not be mathematically treatable. Due to the NP-Hard nature of the problem (Rothkopf et al. 1998), no mathematical algorithm can be applied to simultaneously optimize a complete railway network (Schlechte 2014). Therefore, a tradeoff must be considered between the precision of the obtained results and the efficiency when solving the problem (Schlechte et al. 2011).

Due to this complexity, it is not considered practical to optimize the entire network simultaneously (Borndörfer et al. 2014). A literature review indicates that the development of railway scheduling techniques has been divided into two levels of abstraction, namely microscopic and macroscopic models (Borndörfer et al. 2014). Macroscopic models are usually applied to rail corridors as a whole, whereas microscopic models are usually used for routing trains within the same station, taking into account the dynamics of individual trains, specific tracks, platform assignment, signaling, etc. Figure 1 shows a schematic comparison of both approaches. The left part of the figure represents a microscopic reproduction of Valladolid train station. The horizontal lines represent the tracks, the triangles correspond to railroad switches and the circles represent traffic lights. The right part of the figure illustrates the high speed connections between some Spanish cities. 
Figure 1 Microscopic approach (left) and macroscopic approach (right).

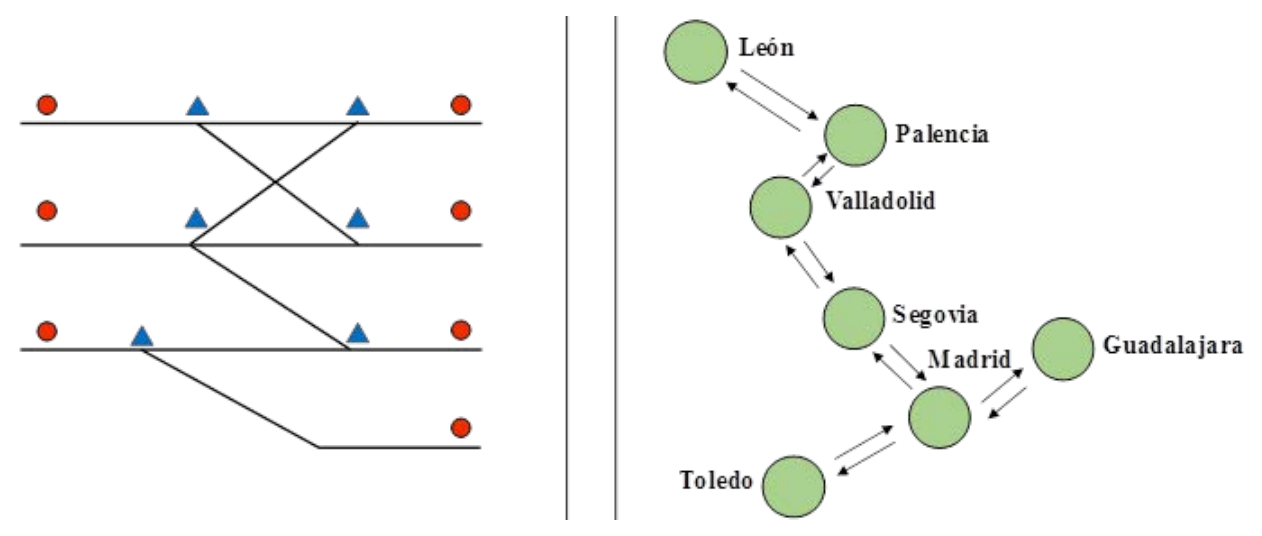

\section{Current perspective: the allocation process in the context of the liberali- zation of the railway market}

other trains) and the connections between nodes represent - in a simplified way - the possible routes between cities. In a microscopic model, the nodes represent railway equipment and contain information on signaling systems while the connections between nodes represent the tracks including information on lengths, gradient, maximum speed on each track segment, etc. (Gille et al. 2008). A macroscopic approach involves the formulation of simplifying hypotheses so that the models are simple enough to apply mathematical optimization techniques to obtain a global schedule for the network. In the microscopic approach, the models are much more detailed, with an exact reproduction of the network infrastructure and train operations. However, these models are built on a small scale.

Railway scheduling has traditionally been addressed at a microscopic level, considering a subdivision of the rail network into the so-called block sections (i.e. track segments where, as a general rule, there can only be one train at a time). The block sections are separated between two signals, which allow the driver to know whether the next block section can be reached. The specific characteristics of each train (speed, acceleration, braking time) were used to route each train along the network. However due to the liberalization of railway transport in recent years, there has been an increasing demand of network segments, and the characteristics of the entire network cannot be considered in this allocation problem. Therefore, nowadays macroscopic models are normally used to route trains between stations, using a simplified version of the infrastructure that allows the application of mathematical optimization tools (Caprara et al. 2002; Borndörfer et al. 2006; Borndörfer and Schlechte 2007). This allows obtaining a tactical scheduling for the railway network, with a defined timetable for each route. However, it will always be necessary to consider real-time traffic along complex stations (and also re-routing issues due to deviations from the initial schedule). This is addressed at a more detailed level and, due to its complexity, only at a local level: at a microscopic level (Caprara et al. 2011).
The current process of liberalization of the railway market promotes the emergence of new train operating companies that will compete for the use of a common railway infrastructure. Therefore, although railway scheduling had been deeply studied for many decades (since the apparition and expansion of the train transport), the liberalization of the railway market makes this allocation process even more complex. In the current version of the problem, there will be one institution in charge of managing the railway infrastructure (the State) that will allocate (sell) the operation rights to several train companies that will compete to use segments of the same network. As in the traditional railway scheduling problem, the whole network is divided into different sections. However, after the liberalization, these railway segments will become 'trade units' that will be sold by the State to the train operating companies. These trade units, which consist of the right to use at a concrete segment of the network for a certain period, are commonly referred to as 'train slots' in the literature. Therefore, the design of mechanisms for the allocation of train slots after the liberalization of the railway market are located at a macroscopic level, according to the paradigms described in Section 2.

As a summary, within this macroscopic context, a literature review shows that the current research in the design of allocation mechanisms of trains slots are being developed in two directions:

\section{A) Design of new macroscopic models}

Considering the NP-hard characteristic of the railway scheduling problem, these investigations are intended to build models with a tradeoff between realism (to provide a useful solution) and simplicity (so that mathematical optimization tools can be applied to obtain a feasible schedule). 
B) Development of mathematical optimization techniques

Using a specific macroscopic model as a starting point, these works aim to develop new mathematical optimization tools to obtain feasible solutions for the railway scheduling problem.

Railway scheduling problem presents a great difficulty in its resolution even for small instances (Erol et al. 2008). Therefore, developing a model on which mathematical optimization techniques can be applied is a key prerequisite to progressing towards solving the large-scale allocation problems (Borndörfer et al. 2010).

Within the macroscopic approach, many works resort to theoretical models based on graphs. In these models, the nodes represent an event that takes place at a specific time and place (e.g. the time a train arrives at a station) whereas the arcs joining the nodes represent movements through the network. We have not found, however, a consensus on the concept of train slot. For some authors, a slot is simply a segment of the network (Caprara et al. 2002). For some others, a slot is a combination of time and space: e.g. the route from the origin to the destination and the time it takes for a train to complete that journey, (Park et al. 2014).

In general, once a macroscopic model has been defined, an optimization problem is formalized: the function to be optimized (i.e. the objective function) is defined (this is normally a magnitude that represents in some way the total utility for all the operating companies) together with a set of constraints (related to the limited capacity of the railway network).

In recent years, there has been an increasing research on the development of mathematical models and optimization approaches to address the railway scheduling problem (Borndürfer et al. 2015). In summary, recent works in this area focus either on the introduction of new hypotheses so that the proposed models better approximate real-world situations, or the development of simulation tools that facilitate finding a solution for the problem (Perennes 2014).

From a mathematical point of view, this optimization problem can be considered as a multi-commodity flow problem through a extremely large network (both in space and time) with a set of additional constraints (Schlechte 2011). This problem has been widely studied in the literature, and Caprara et al. (2002) demonstrate that it is NP-hard.

In many articles (Borndörfer and Schlechte (2007), Borndörfer et al. (2009a, 2010) to cite a few), this problem is addressed by means of integer linear programming. These mathematical approaches cannot be addressed with standard solvers (Fischer and Schlechte 2015). For this reason, over the last few years several approaches based on relaxation methods have been developed, which allow obtaining limits around the optimum solution. Some of these approach- es are based on column generation techniques (Borndörfer and Schlechte 2008; Park et al. 2014) , lagrangian relaxation (Borndörfer and Schlechte 2007; Fischer and Schlechte 2017), LP relaxation (Borndörfer and Schlechte 2008), rapid branching techniques (Borndörfer et al. 2010; Borndörfer et al. 2013) or bounding by dual relaxations techniques (Fischer and Schlechte 2015).

Furthermore, it is not only a matter of finding an optimal schedule. Since train slots are to be traded, it would be desirable that each train slot was allocated to that company that values that slot the most. Addressing this allocation problem with linear programming techniques has a main disadvantage: in order to find an optimal solution, train operating companies would need to reveal their preferences for each trains slot, which is something they would certainly not be willing to do. To overcome these issues, in this paper we propose to use combinatorial auctions in this allocation process as it has provided successful results after the liberalization of other markets such as radio spectrum or airport traffic management.

\section{Methodological approach: combinato- rial auctions}

An auction is a market mechanism that allows an item (usually a scarce resource) to be allocated to the entity that values it most. In the case of the liberalization of the railway market, the limited resource to be auctioned would be the right to use a track segment for a given time. However, a traditional auction approach would not be enough to solve this allocation problem. As a matter of example, let us suppose that a train operating company is interested in connecting two cities. If the railway segments connecting those cities were auctioned, that operator would need to bid on all the segments separating the two cities (each of them at a specific time). In this situation, the utility obtained by the operator would depend on whether they obtain all the required segments for a feasible connection between the two cities. If they do not obtain all the needed segments (for example, because one of the segments has been allocated to other operator) the utility for the company would be of very limited if any value.

To solve these issues, there exists a specific auction mechanism to be used when the items auctioned are considered as complementary goods by the bidders: the combinatorial auction. A combinatorial auction is a specific type of auction in which the bidders have the possibility on bidding on different combinations of items (Villafáñez and Poza 2010). This is to say, a bidder can offer different amounts of money for each lot of items being auctioned.

In general, a combinatorial auction of $n$ items yields $2 n-1$ combinations (lots) of items. Consequently, any participant in the auction would be able to place a bid for any of these $2 \mathrm{n}-1$ lots of items. Figure 2 shows a schematic example of a combinatorial auction of three items, which gives rise to sev- 
en lots of items. If a bidder is interested in acquiring the blue and the green item (because she considers these two items as complementary) she can place a bid for the lot of these two items and not bid on any of these items individually (because acquiring one of these items is of no use if the other item is not acquired).

Figure 2 Seven possible lots of items in a combinatorial auction of three items.

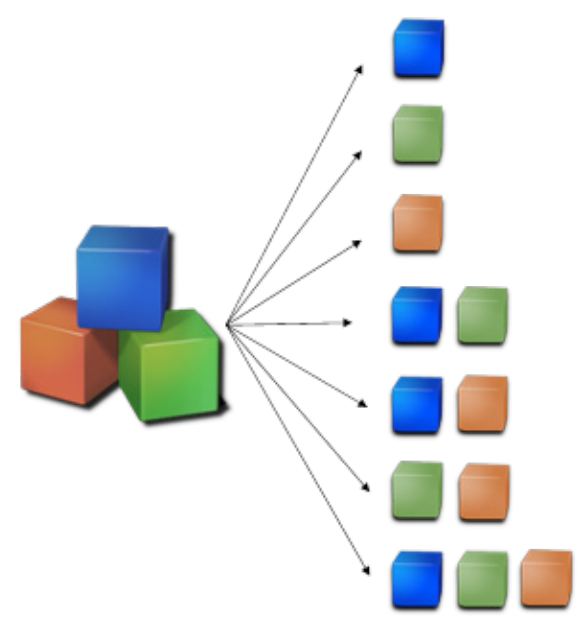

In the last decades, the use of combinatorial auctions has been proposed for the resolution of complex allocation problems in a large number of very varied domains: allocation of resources in multi-project environments (Arauzo et al. 2009; Villafáñez and Poza 2010), assignment of vendors (Epstein et al., 2002), distribution routes (Caplice 1996), the design of a 3D printing market (López-Paredes et al. 2018; López-Paredes et al. 2019), etc. More concretely, combinatorial auctions have been proposed to solve allocation problems derived from the liberalization of markets: allocation of time slots in large airports (Ramírez et al. 2014; Araúzo et al. 2018) or frequency spectrum (McMillan 1994). Furthermore, some recent research demonstrates that auction-based mechanisms can provide a more resilient approach to the optimization of NP-hard problems (Villafáñez et al. 2019).

In the railway field, a few recent papers assess using auctions for the allocation of slots to train operating companies versus the traditional administrative methods: Borndörfer et al. (2006, 2009b); Park et al. (2014); Perennes (2014); Kuo and Miller-Hooks (2015). However, we have not found any work that describes the auction mechanism in detail (i.e. how bids are made, how prices are formed, etc.). This is why in the next section we present a pilot model as the first step to the design of a combinatorial auction for the liberalization of the Spanish railway transport.

\section{A pilot model of the design of the combinatorial auction}

\subsection{Problem description}

According to the EU directives for the liberalization of the railway market, a state-owned company (ADIF in the case of the Spanish railway) will be responsible for allocating the slots to the train operating companies. To this aim, we propose to use a combinatorial auction in which the auctioneer will be ADIF, the items auctioned will be the railway slots, and the bidders will be the train operating companies interested in operating in the Spanish railway system.

Let us consider the simplified macroscopic model shown in Figure 3. This graph represents the possible connections between six cities (A, B, C, D, E and F). To keep the explanation simple, let us consider that it takes one hour for a train to complete a segment (i.e. the journey from a node to any of its adjacent nodes). In this simplified example we will consider that a railway slot is defined as the right to use a segment between two nodes for a one-hour period. This infrastructure will be shared between the train operating companies interested in operating some of the connections within this network. 
Figure 3 A simplified macroscopic model for the problem description.

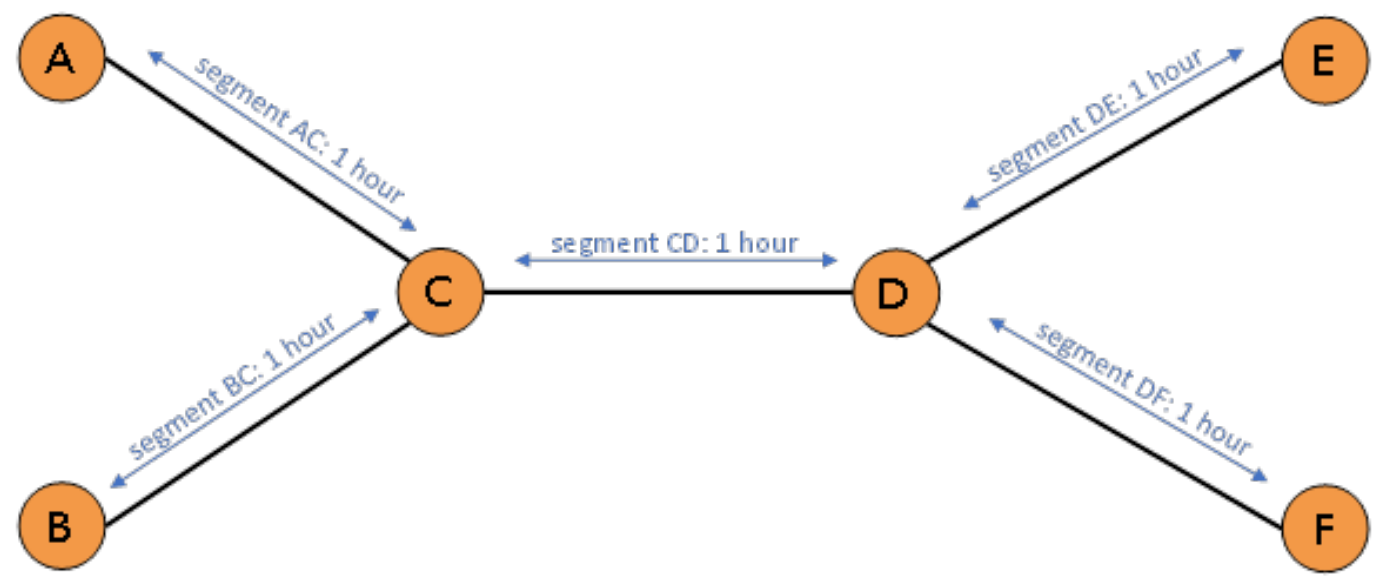

To cover a route between two cities, it is required that a company acquires all the slots associated to all the segments connecting those two cities at the times they are needed. For example, if a company wants to cover the route A-C-D-E leaving from $A$ at 6:00, they must acquire the following three slots: $\mathrm{AC}_{6: 00}, \mathrm{CD}_{7: 00}$, and $\mathrm{DE}_{8: 00}$ (recall that each city is onehour away from its adjacent cities).

Train operating companies will face a decision problem when assessing the profitability of operating a concrete route. The expected utility will depend on the passenger demand on that route at the time the company is willing to cover the route. Going back to the previous example (route A-C-D-E leaving from $A$ at 6:00), the utility will be a function of the combination of four passenger demands: the demand for the complete journey from A to $\mathrm{E}$ and the demands for the three sub-routes connecting the intermediate stopping locations. Namely: the demand for the route $A_{6: 00}-E_{9: 00}$ (i.e. passengers who board the train at 6:00 in $A$ and leave the train at 9:00 in $\mathrm{E}$ ), the demand for the route $\mathrm{A}_{6: 00}-\mathrm{C}_{7: 00}$ (i.e. passengers taking the train at 6:00 in $\mathrm{A}$ and leaving the train at 7:00 in $\mathrm{C}$ ), the demand for the route $\mathrm{C}_{7: 00}-\mathrm{D}_{8: 00}$ (i.e. passengers taking the train at 7:00 in $C$ and leaving the train at 8:00 in D), and the route $\mathrm{D}_{8: 00}-\mathrm{E}_{9: 00}$ (i.e. passengers who board the train at 8:00 in $\mathrm{D}$ and leave the train at 9:00 in $\mathrm{E}$ ).
However, the decisions made on covering a route at a specific time of the day will condition the possibility of covering other routes later on the same day. Going back to the example, if the company's train arrives in $\mathrm{E}$ at 9:00, due to the network connections (Figure 3), the only route they will be able to operate from that node at that time will be the route $E_{9: 00}-D_{10: 00}$. Once in D at 10:00, the company has three options: going back to $\mathrm{E}$ (route $\mathrm{D}_{10: 00}-\mathrm{E}_{11: 00}$ ), going to $\mathrm{C}$ (route $\mathrm{D}_{10: 00}-\mathrm{C}_{11: 00}$ ) or going to $\mathrm{F}$ (route $\mathrm{D}_{10: 00}-\mathrm{F}_{11: 00}$ ). The decision made by the company will be conditioned by the estimation of the demand for each of these three routes, which will be, in turn, conditioned by the demand for the possible routes departing from the nodes $\mathrm{E}, \mathrm{C}$ or $\mathrm{F}$ (which depends on the company's previous decision) an so forth.

This means that companies interested in operating their trains in this infrastructure face a combinatory decision problem: when maximizing their utility, they must consider all the possible combinations of routes along the day and the demand for each of those routes at the times they will be operated. Figure 4 illustrates the combinatory explosion in the company's decisions. For simplicity purposes, we have only represented the period 6:00 to 10:00. We have also assumed negligible boarding times (i.e. there is no waiting time at the stations). 
Figure 4 Possible combinations of routes when deciding to leave a node at certain time. Representation from 6:00 a $10: 00$

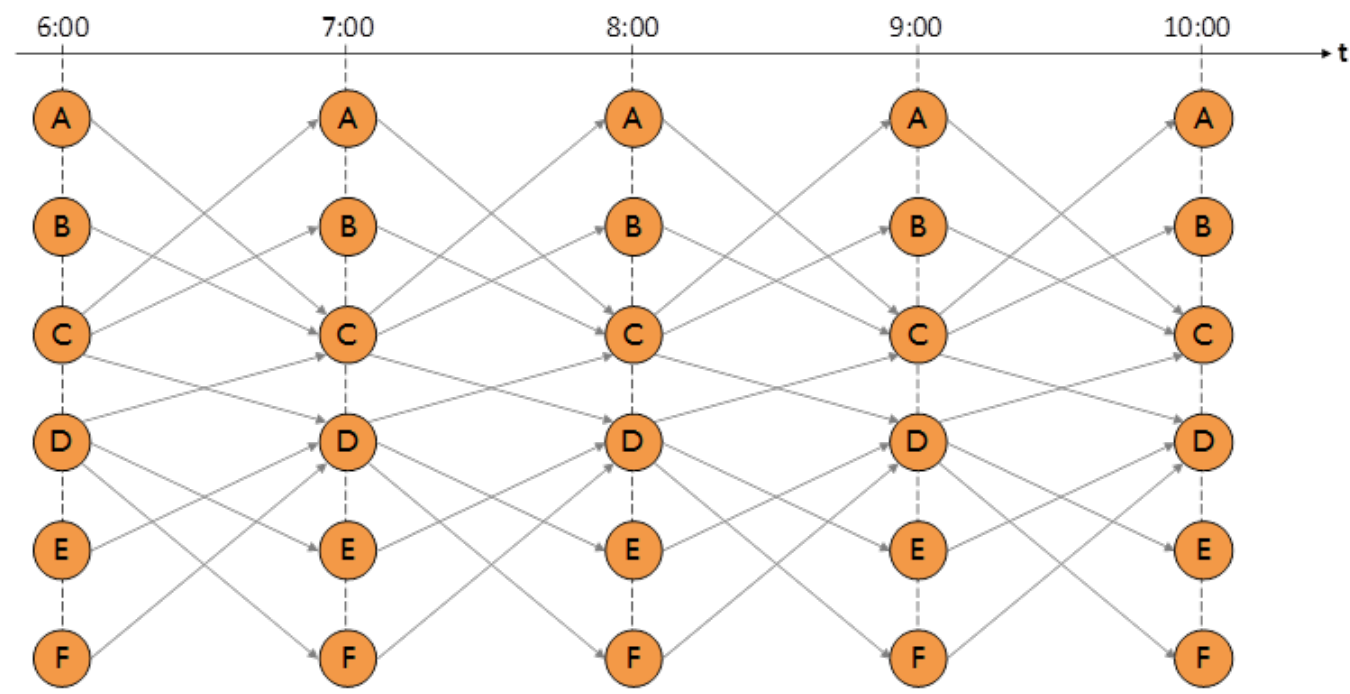

Therefore, to maximize their utility, a company must consider the passenger demand in all the possible combinations of succession of links in the network shown in Figure 4.

Being aware of this complexity, in our pilot model we have considered a company's utility in a simplified way. The utility function for a company when operating a route will be a stepped line graph in which the maximum utility would be reached if the company can operate that route at the desired time. An example is shown in Figure 5. The utility for this route will be maximum if the company manages to get the required slots to operate the train departing at 6:00. Covering the same route but leaving one hour later would mean a lower utility for the company. The utility would be even lower if it the train leaves at 8:00 and so on. Recall that in a more general case, a route's utility is a function of the expected income when operating that route at a specific time, which in turn depends of the expected number of passengers, the prices (and the possibility of segmenting the consumers), etc.
Figure 5 A simplified way of modeling a company's utility.

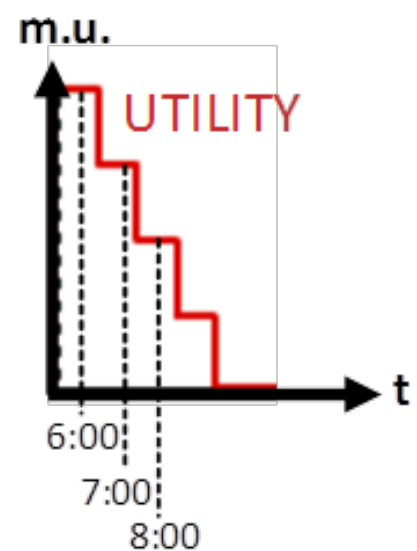


Once the company has decided what routes to cover, the company will be charged for the use of the required slots (i.e. the required infrastructure segments at the times they are needed). The prices of each slot will be determined by means of a combinatorial auction. This price is subject to change during the course of the combinatorial auction, depending on the potential bids for the same slots by other train operating companies.

\subsection{Auction description}

The auction in the pilot model will be composed of two phases: a preliminary phase and an allocation phase. In the preliminary phase, the auctioneer (i.e. the infrastructure manager) will receive multiple bids from several companies. These petitions will be analyzed as some of them might be incompatible with one another and may be discarded. The preliminary phase ends when the infrastructure manager decides the final set of routes that will be auctioned. Then, in the allocation phase, the operator who will cover each route will be determined by means of a combinatorial auction. This auction will be composed of several rounds, in which the train companies will be able to offer certain amount of money for the slots required to cover their routes. The combinatorial auction will end when a final allocation is achieved.

Here, we describe the operations of the allocation phase with an example. Let us suppose that there are three companies (blue, red and green) competing to operate the following routes: the red company wants to connect the node A with the node E, leaving A at 6:00. Due to the network structure and the assumption that it takes one hour to reach an adjacent node, this connection requires using the following slots: $\mathrm{AC}_{6: 00}, \mathrm{CD}_{7: 00}$ and $\mathrm{DE}_{\text {8:00. }}$ Similarly, the green company, who wants to leave $B$ at 6:00 to reach $F$ at 9:00, will need to use the following slots: $\mathrm{BC}_{6: 00}, \mathrm{CD}_{7: 00}$ and $\mathrm{DF}_{8: 00}$. Finally, the blue company, who wants to connect $\mathrm{C}$ and $\mathrm{D}$ (leaving $\mathrm{C}$ at 8:00) will need to use the slot $C D_{8: 00}$. The required slots according to the desired schedules by the three companies are shown in Figure 6.
Figure 6 Required slots according to the desired schedules by the three companies.
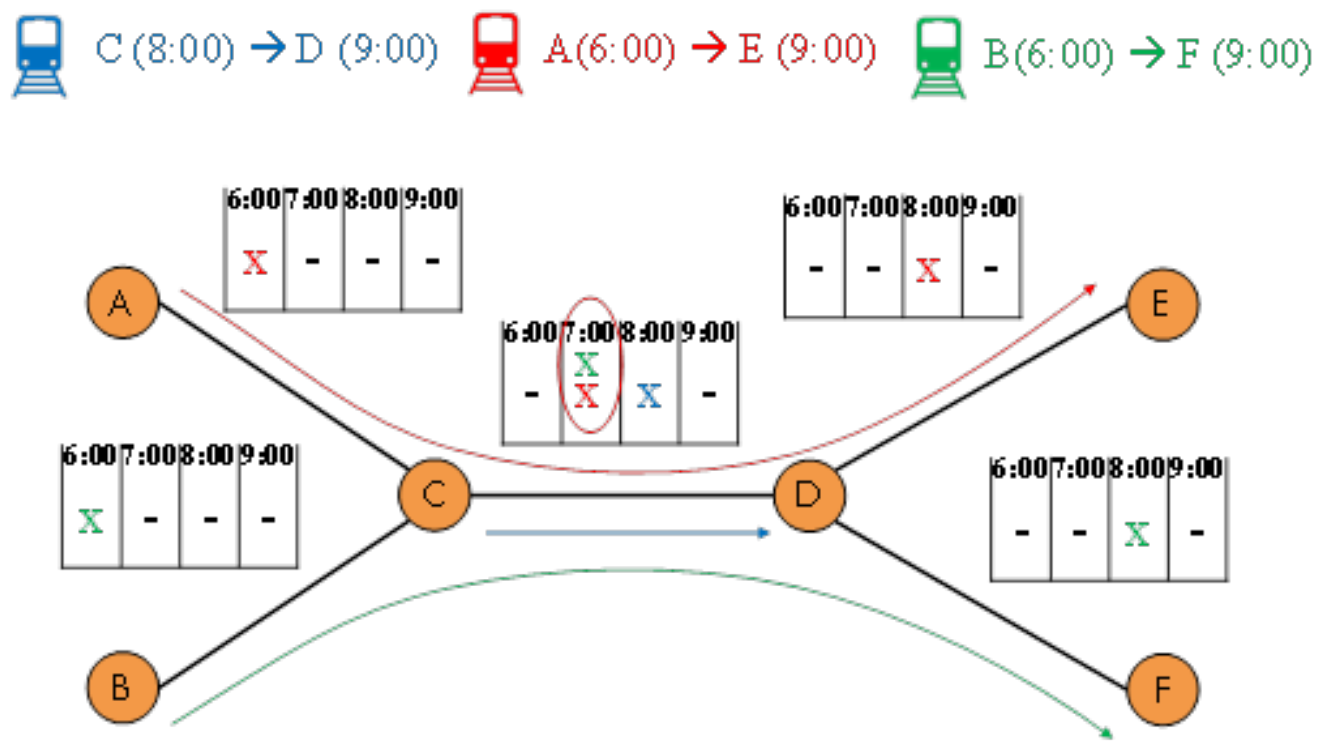

In each round of the auction, the operating companies will have the opportunity to offer a price for the slots in which they are interested. Figure 7 shows the prices offered for each slot by the three companies (the sub index represents the round number). 
Figure 7 Prices offered for each slot by the three train operating companies.

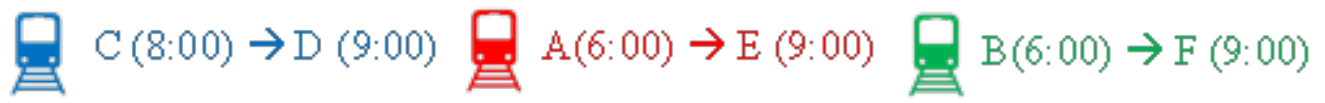

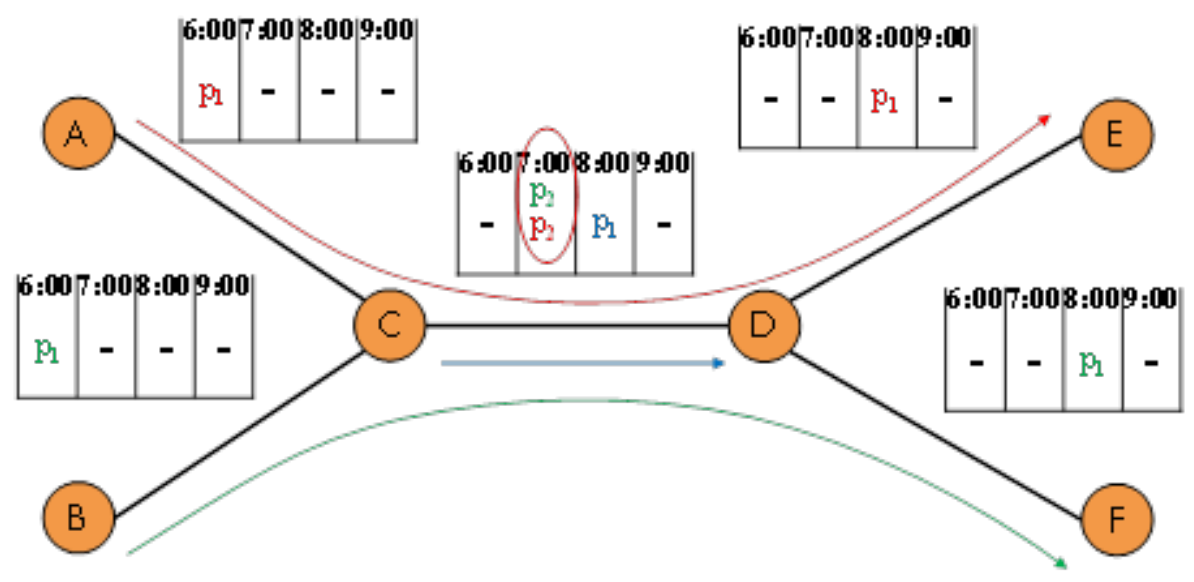

In the cases where only one company is interested in a concrete slot, the company will not need to increase the bid in the next round. This is the case of the following slots: $\mathrm{AC}_{6: 00}$, $\mathrm{BC}_{6: 00}, \mathrm{CD}_{8: 00}, \mathrm{DE}_{8: 00}$ and $\mathrm{DF}_{8: 00}$. The price offered for these slots remains as $\mathrm{p}_{1}$, which was the price offered for these slots in the first round. However, if two or more companies are interested in the same slots, they will need to raise their bids in subsequent rounds in an attempt to obtain those slots. This case is highlighted in Figure 7: Since the red company and the green company are both interested in using the same slot: $\mathrm{CD}_{7: 00}$, they will probably try to overbid each other to gain those slots (in Figure 7, ' $\mathrm{p}_{2}$ ' indicates the new prices offered for these slots in the second round).

As far as the prices are concerned, each company will have to pay the sum of the slot prices comprising the route they want to cover, as shown in Figure 8.
Figure 8 Prices paid by each company

(if they obtain the slots).

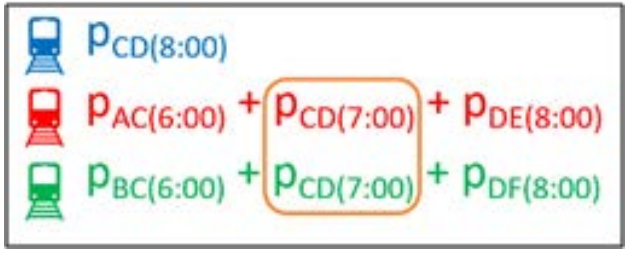

Let us take the red company as an example and assume that its utility when covering the route A-C-D-E is given by the plot shown in Figure 5. This company will achieve a maximum utility if it manages to get the required slots to operate the route $A-C-D-E$ departing from $A$ at 6:00. If the price of the slot $\mathrm{CD}_{7: 00}$ (Figure 8) is becoming so high that makes red company's surplus become negative, it will might consider covering the same route A-C-D-E one hour later (leaving from $A$ at 7:00 instead of 6:00). One the one hand, this new strategy will result in a lower utility (according to Figure 5), but, on the other hand, it entails using 'cheaper' slots: as a whole, this new strategy brings a higher surplus to the company. Figure 9 shows red company's new demand for slots at a later round of the auction. 
Figure 9 A shift in the slots demanded by the red company.
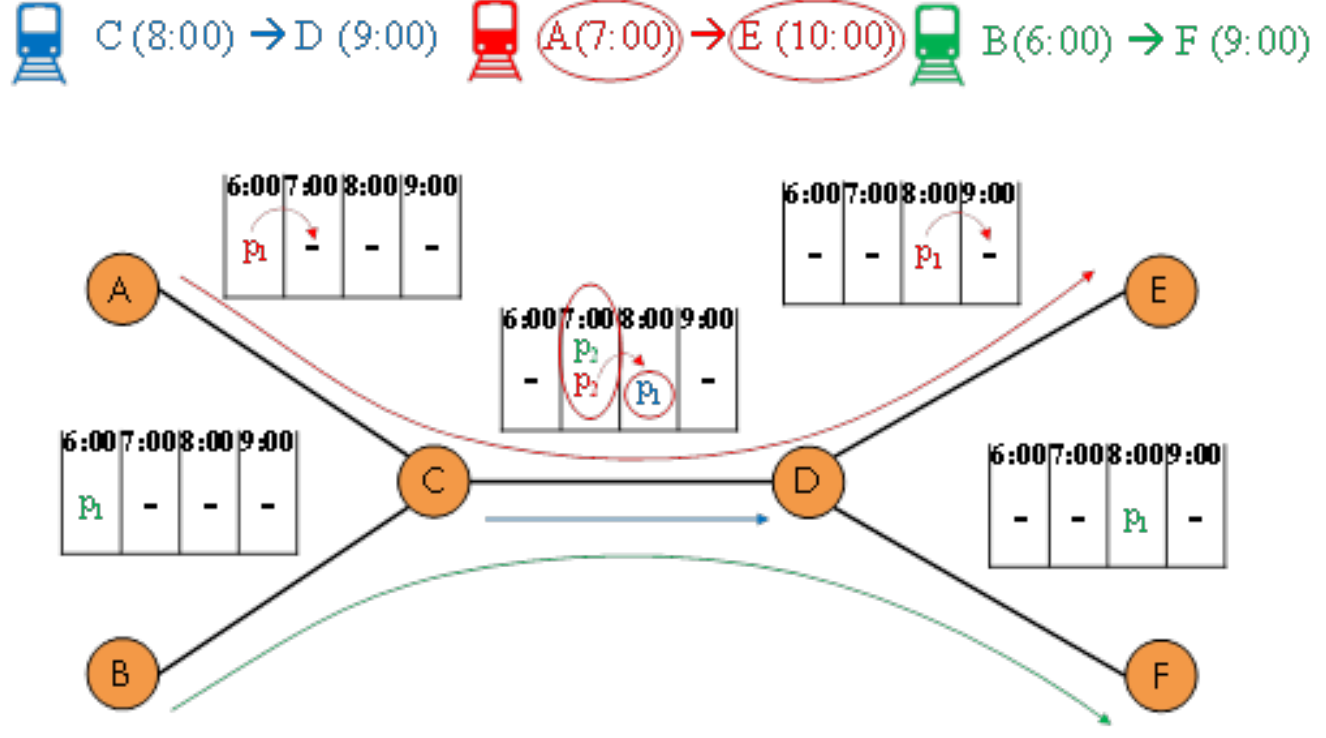

This new strategy involves using the slot $\mathrm{CD}_{8: 00}$, a slot in which the blue company was interested from the beginning of the auction (Figure 6). It is expected that a new competition starts between the red company and the blue company to acquire these two slots over the next rounds (which will result in a price increase in these slots and probably to new shifts in the slots demanded by the companies). The combinatorial auction will end will a final allocation is achieved.

The design of this pilot model will serve us as a basis for the implementation of a combinatorial auction that helps the infrastructure manager (ADIF) to allocate slots to the new train operating companies during the liberalization process in the Spanish railway market.

\section{Conclusions and future developments}

Although this paper is not a survey on railway scheduling, we have provided a review on previous research on mechanisms for railway scheduling (i.e. finding a feasible timing so that a set of trains can operate without conflicts through a railway network during a certain period) in the context of the liberalization of the railway market in the European Union. We find that many previous studies resort to linear programming techniques in an attempt to find a feasible schedule that meets the constraints derived from the limited capacity of the railway networks. However, the NP-hard nature of this problem makes it difficult for these methods to obtain a feasible solution in practical cases. Furthermore, these optimization techniques would require train operating companies to reveal private information (e.g. what railway segments and periods are more valuable to them).

To overcome these issues, in this paper we have proposed the use of combinatorial auctions for the allocation of slots to train operating companies, as this market mechanism has provided successful results in the allocation of limited re- sources after the liberalization of other markets such as radio spectrum airport traffic management. We claim that governments will benefit from the incorporation of this mechanism as it provides a greater social welfare than traditional administrative allocation processes such as competitive tenders or lotteries. Future developments will provide an implementation of this pilot model that will allow the allocation of slots to train operating companies within the Spanish railway system.

Funding. This research has been partially financed by the project ABARNET (Agent-Based Algorithms for Railway NETworks optimization) financed by the Spanish Ministry of Economy, Industry and Competitiveness with grant DPI2016-78902-P, and the project "Lonja de Impresión 3D para la Industria 4.0 y la Empresa Digital (LONJA3D)" funded by the Regional Government of Castile and Leon and the European Regional Development Fund (ERDF, FEDER) with grant VA049P17.

\section{References}

Arauzo JA, Galán JM, Pajares J, López-Paredes A (2009) Multi-agent technology for scheduling and control projects in multi-project environments. An Auction based approach. Intel Artif 13:12-20. doi: 10.4114/ia. v13i42.1042

Araúzo JA, Villafáñez FA, García DP, et al (2018) Agent based modelling and simulation of an auction market for airport slots allocation. In: Communications in Computer and Information Science. pp 456-467

Borndörfer R, Erol B, Graffagnino T, et al (2014) Optimizing the Simplon railway corridor. Ann Oper Res 218:93106. doi: 10.1007/s10479-012-1260-9 
Borndörfer R, Erol B, Schlechte T (2009a) Optimization of macroscopic train schedules via TS-OPT. In: Hansen I, Wendler E, Weidmann U, et al. (eds) Proceedings of the 3rd International Seminar on Railway Operations Modelling and Analysis - Engineering and Optimisation Approaches.

Borndörfer R, Grötschel M, Lukac S, et al (2006) An auctioning approach to railway slot allocation. Compet Regul Netw Ind 1:163-197. doi: 10.1177/178359170600100204

Borndörfer R, Löbel A, Reuther M, et al (2013) Rapid branching. Public Transp 5:3-23.

Borndörfer R, Mura A, Schlechte T (2009b) Vickrey auctions for railway tracks. In: Operations Research Proceedings 2008. Springer, pp 551-556

Borndörfer R, Schlechte T (2007) Models for Railway Track Allocation. In: 7th Workshop on Algorithmic Approaches for Transportation Modeling, Optimization, and Systems. pp 62-78

Borndörfer R, Schlechte T (2008) Solving Railway Track Allocation Problems. Oper Res Proc 2007 20:117-122.

Borndörfer R, Schlechte T, Swarat E (2012) Railway Track Allocation - Simulation, Aggregation, and Optimization. Proc 1st Int Work High-speed Intercity Railw (IWHIR 2011) 2:53-70. doi: 10.1007/978-3-642-27963-8

Borndörfer R, Schlechte T, Weider S (2010) Railway track allocation by rapid branching. In: OASIcs-OpenAccess Series in Informatics. Schloss Dagstuhl-Leibniz-Zentrum fuer Informatik, pp 13-23

Borndürfer R, Lamorgese L, Reuther M, et al (2015) Recent Success Stories on Optimization of Railway Systems. ZIB-Report 14:26.

Caplice CG (1996) An Optimization Based Bidding Process: A New Framework for Shipper-Carrier Relationships. 250.

Caprara A, Fischetti M, Luigi Guida P, et al (2001) Solution of real-world Train Timetabling Problems. Proc Hawaii Int Conf Syst Sci 00:76. doi: 10.1109/HICSS.2001.926325

Caprara A, Fischetti M, Toth P (2002) Modeling and Solving the Train Timetabling Problem. Oper Res 50:851-861. doi: $10.1287 /$ opre.50.5.851.362

Caprara A, Galli L, Toth P (2011) Solution of the train platforming problem. Transp Sci 45:246-257.
Epstein R, Henríquez L, Catalán J, et al (2002) A combinational auction improves school meals in Chile. Interfaces (Providence) 32:1-14.

Erol B, Klemenz M, Schlechte T, et al (2008) TTPlib 2008 - A library for train timetabling problems. WIT Trans Built Environ 103:605-614. doi: 10.2495/CR080591

Fischer F, Schlechte T (2015) Comparing two dual relaxations of large scale train timetabling problems. In: Proceedings of Conference on Advanced Systems in Public Transport 2015.

Fischer F, Schlechte T (2017) Strong Relaxations for the Train Timetabling Problem Using Connected Configurations. In: OASIcs-OpenAccess Series in Informatics. Schloss Dagstuhl-Leibniz-Zentrum fuer Informatik,

Garey MR, Johnson DS (1979) Computers and Intractability: A Guide to the Theory of NP-Completeness (Series of Books in the Mathematical Sciences). Comput Intractability. doi: $10.1137 / 1024022$

Gille A, Klemenz M, Siefer T (2008) Applying multiscaling analysis to detect capacity resources in railway networks. WIT Trans Built Environ 103:595-603.

Kuo A, Miller-Hooks E (2015) Combinatorial auctions of railway track capacity in vertically separated freight transport markets. J Rail Transp Plan Manag 5:1-11. doi: 10.1016/j.jrtpm.2014.12.001

López-Paredes A, de Anton J, Senovilla JJ, et al (2019) Production Optimization in 3Dprinting manufacturing factories. In: 13th International Conference on Industrial Engineering and Industrial Management" and “XXIII Congreso de Ingeniería de Organización (CIO2019).

López-Paredes A, Pajares J, Martín N, et al (2018) Application of Combinatorial Auctions to create a 3Dprinting market. In: 12th International Conference on Industrial Engineering and Industrial Management - XXII Congreso de Ingeniería de Organización (CIO 2018).

McMillan J (1994) Selling Spectrum Rights. J Econ Perspect 8:145-162. doi: 10.1257/jep.8.3.145

Park BH, Hong SH, Kim CS (2014) A new optimization model for railway slot allocation. WIT Trans Built Environ 135:613-620. doi: 10.2495/CR140511

Perennes P (2014) Use of combinatorial auctions in the railway industry: Can the "invisible hand" draw the railway timetable? Transp Res Part A Policy Pract 67:175-187. doi: 10.1016/j.tra.2014.07.002 
Ramírez M, Villafáñez FA, Araúzo A, López-Paredes A (2014) Agent-based pilot model for alternative primary airport slot allocation with price-setting auctions preliminary results of the ACCESS project. In: SIDs 2014 Proceedings of the SESAR Innovation Days.

Rothkopf MH, Pekeč A, Harstad RM (1998) Computationally Manageable Combinational Auctions. Manage Sci 44:1131-1147. doi: 10.1287/mnsc.44.8.1131

Schlechte T (2011) Railway track allocation -simulation and optimization. In: Proceedings of 4th International Seminar on Railway Operations Modelling and Analysis (IAROR).

Schlechte T (2014) Railway Track Allocation. In: Helber S, Breitner M, Rösch D, et al. (eds) Operations Research Proceedings 2012: Selected Papers of the International Annual Conference of the German Operations Research Society (GOR), Leibniz University of Hannover, Germany, September 5-7, 2012. Springer International Publishing, Cham, pp 15-20
Schlechte T, Borndörfer R, Erol B, et al (2011) Micro-macro transformation of railway networks. J Rail Transp Plan Manag 1:38-48. doi: 10.1016/j.jrtpm.2011.09.001

Villafáñez F, Poza D, López-Paredes A, et al (2019) A generic heuristic for multi-project scheduling problems with global and local resource constraints (RCMPSP). Soft Comput 23:3465-3479. doi: 10.1007/s00500-0173003-y

Villafáñez F, Poza DJ (2010) Propuesta de Modelo MAS para la resolución del RCMPSP basado en Subastas Combinatorias. In: Gutiérrez Pajares J, López-Paredes A, Iglesias Hernández C (eds) Best Practices in Project Management. Methodologies and case studies in Construction and Engineering. pp 153-165 